\title{
Evoked potential changes in clinically definite multiple sclerosis: a two year follow up study
}

\author{
JC WALSH, R GARRICK, J CAMERON, JG MCLEOD \\ From the Department of Neurology, The Royal Prince Alfred Hospital, Camperdown NSW 2050, Australia
}

SUMMARY Visual, spinal and somatosensory evoked potentials were performed on 56 patients with clinically definite multiple sclerosis at the beginning and end of a $2 \frac{1}{2}$ year follow-up period. At the initial examination one or both visual evoked potentials were abnormal in all but nine patients $(84 \%)$, five of whom had abnormalities of either spinal or somatosensory evoked responses; that is, one or more abnormal results were obtained from 52 of $56(91 \%)$ patients. At the final examination there were abnormalities of one or more evoked potentials in 55 of the 56 $(98 \%)$ patients. There was an increase in latency of the components of the evoked responses over the period; reduction in latency in individual patients was exceptional. The change in these electrophysiological measurements correlated with the increase in clinical disability of the group of patients over the period of study.

The study of the responses evoked in the electroencephalogram by sensory stimuli provides objective information about conduction within the central nervous system and is one of the most important developments in clinical neurophysiology in the past 50 years. ${ }^{12}$ One major application of these techniques has been to the investigation of patients suffering from multiple sclerosis. The visual evoked potential (VEP) to pattern reversal is most frequently employed, ${ }^{3-5}$ but spinal (SPEP) ${ }^{67}$ and cortical potentials (CEP) ${ }^{8-10}$ in response to stimulation of the peripheral nerves, and early brain stem responses to click stimuli (BSAEP) ${ }^{11}$ are also used both as single and as combined studies. ${ }^{12-14}$

There have been a number of reports of the frequency of the abnormalities of evoked potentials in multiple sclerosis, ${ }^{379101214}$ but many of these include cases that were not clinically definite. There have been few previous studies reported of the changes that occur in the evoked potentials over a period of time in patients with multiple sclerosis. ${ }^{15-18}$ For these reasons we report the results of visual, spinal, somatosensory and auditory evoked potentials obtained from 56 patients who were followed for a period of over two years with clinically definite multiple sclerosis, ${ }^{19}$ with the object

Address for reprint requests: Dr J Walsh, Department of Neurology, Building 92, Royal Prince Alfred Hospital, Missenden Road, Camperdown, New South Wales, 2050, Australia.

Received 22 July 1981 and in revised form 15 January 1982. Accepted 30 January 1982 of determining both the frequency of abnormalities, and the alterations that occur in the latency of the major components of the evoked potentials over this interval of time.

\section{Materials and methods}

\section{Patients}

Sixty patients with clinically definite multiple sclerosis ${ }^{19}$ were selected following established criteria and took part in a clinical trial of transfer factor. ${ }^{20}$ In the present report the results obtained from the placebo and treated groups have been pooled as there was no significant difference between the electrophysiological studies in the groups at any stage in the trial. ${ }^{20}$ Visual, spinal and cortical sensory evoked responses were studied in each patient at the beginning of the trial, and at about six months intervals for at least two years. Brain stem auditory evoked responses were introduced after the onset of the trial and results are not available on all patients. The photographic records of the responses were reviewed, and measurements on a small number of individual responses have been excluded from the data because the response was technically unsatisfactory (table 3 ).

\section{Visual evoked potentials}

A reversing checkerboard pattern which subtended $25^{\circ}$ at the eye was projected from a rotating mirror on to a screen. Each check subtended $55^{\prime}$ and reversal occurred in less than $10 \mathrm{~ms}$. A single channel of EEG was recorded from an active electrode in the mid-line $5 \mathrm{~cm}$ above the inion, referred to $\mathrm{Fz}$, and $300 \mathrm{~ms}$ epochs were averaged after amplification and filtering with a band pass of $0 \cdot 32-3200$ $\mathrm{Hz}$. The latency to the first major positive component (P $\overline{100}$ ) was measured from photographic records. 


\section{Spinal and somatosensory evoked potentials}

An electrical stimulus was applied to the median nerves at the wrist to produce moderate contraction of the abductor pollicis brevis muscle. Active electrodes were placed over the second cervical vertebral spine and over the contralateral hand area and referred to $\mathrm{Fz} ; 20 \mathrm{~ms}$ epochs of EEG were averaged after amplification with a band pass of 8$8000 \mathrm{~Hz}$ to define the spinal evoked potential, and $200 \mathrm{~ms}$ epochs of EEG were averaged after amplification with a band pass of $0 \cdot 32-3200 \mathrm{~Hz}$ to define the cortical evoked potential. The latency of the major negative $(\mathrm{N} \overline{13})$ component of the spinal evoked potential, and first negative $(\mathrm{N} \overline{20})$ and following positive (P $\overline{30}$ ) component of the cortical evoked potential were measured. The conduction of the peripheral segment of the median nerve was studied at the beginning and conclusion of the study by measuring either sensory conduction velocity in the forearm segment of the nerve or by recording the response from Erb's point (N 9).

\section{Auditory brain stem evoked potentials}

A click of $500 \mu$ s duration and $70 \mathrm{db}$ above the patient's threshold was applied to each ear, and $10 \mathrm{~ms}$ epochs of EEG obtained from electrodes on the earlobe and vertex were averaged after amplification with a band pass of $32-8000 \mathrm{~Hz}$. At least two averages were obtained from each ear and the latency to peak of component $V$ was measured. Latency measurements were compared using the two-tailed Student $t$ test and are expressed as the mean and standard deviation (SD).

\section{Results}

There were 56 patients with clinically definite multiple sclerosis for whom results were available at the beginning and end of the follow-up period. The results are summarised in tables 1-3. Only the latencies of the major components of the wave form were considered; the amplitudes were not compared because of the wide range of variability in control subjects. Clinical disability was assessed at the beginning and end of the follow-up period and was graded on the Kurtzke Disability scale. ${ }^{20}$ At the conclusion of the study there were 37 patients who had deteriorated clinically and 16 patients who were unchanged. One or more evoked response component had increased in latency in each of these patients. There were three patients who had improved clinically over this period; one or more evoked response component had increased in latency in two of these patients, and all evoked responses remained unaltered in one patient.

\section{VISUAL EVOKED POTENTIALS}

\section{Controls}

The mean latency to peak of the first major positive component, commonly termed the $P \mathbf{1 0 0}$ component was $89 \pm 7 \mathrm{~ms}$ and the mean +2 SD was $103 \mathrm{~ms}$ in
50 control subjects; the upper limit for the inter-eye difference in any subject was $5 \mathrm{~ms}$. The $P 100 \mathrm{com}$ ponent was considered abnormal if the latency was more than 2 standard deviations greater than the control mean $(103 \mathrm{~ms})$ or if the inter-eye difference was $6 \mathrm{~ms}$ or longer.

\section{Patients}

At the first examination, 47 patients had abnormal responses $(84 \%)$; of these, 17 patients had abnormal responses in one eye only. The mean latency for the group was $113.8 \mathrm{~ms}$ (SD, $27.5 \mathrm{~ms}$ ). There were four patients with a unilateral absent response. A total of 73 abnormal responses to monocular stimulation was obtained at the first examination and there was clinical evidence from history or physical examination to suggest that the disease may have involved 52 of these eyes $(73 \%)$. There were 39 eyes from which normal responses were obtained. There was historical evidence suggesting previous visual impairment in 15 of these $(39 \%)$ and objective abnormalities on clinical examination in three eyes.

The studies were repeated after a mean interval of 31.6 months when 51 patients $(91 \%)$ had one or more abnormal responses (table 2) (fig 1). No response could be obtained from 11 eyes. An increase or decrease in latency of $5 \mathrm{~ms}$ was considered a significant change. There were 65 eyes in which the latency had increased, 38 that were unchanged and nine in which the latency had decreased (table 3 ). In one patient the latency decreased from $160 \mathrm{~ms}$ to $135 \mathrm{~ms}$ in the right eye and the amplitude increased, without significant change in the left eye. This latency change was paralleled by a change of acuity in the right eye from $6 / 9$ to $6 / 5$, and in the left eye from $6 / 7.5$ to $6 / 5$. In another patient the latency decreased from $109 \mathrm{~ms}$ to $103 \mathrm{~ms}$ in the left eye, without significant change in the right eye; the corresponding changes in acuity were from $6 / 6$ to $6 / 5$ in both eyes. There was clinical improvement in five eyes at the final examination; the latency of the $P \overline{100}$ component was reduced in three of these but had increased in two. There were 74 eyes which were clinically unaltered; in this group 39 responses were worse, 29 were unchanged and six had improved. Clinical deterioration had occurred in the remaining 33 eyes; the response was worse in 27 of these, and had not altered in six.

SOMATOSENSORY EVOKED POTENTIALS There were 53 patients in whom spinal and cortical somatosensory responses were recorded at the beginning and end of the period of follow up, and of these there were 48 with clinical evidence of sensory disturbance at the first examination. Four of the five 
Table 1 The latency of major components of evoked potentials in a group of 56 patients with clinically definite multiple sclerosis at the first examination compared with results obtained from a group of control subjects

\begin{tabular}{|c|c|c|c|c|}
\hline Components & Controls & $\begin{array}{l}\text { Patients } \\
\text { First Study }\end{array}$ & $\begin{array}{l}\% \text { patients } \\
\text { abnormal }\end{array}$ & $P_{2}$ \\
\hline 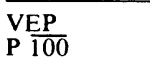 & $89 \cdot 0 \pm 7 \cdot 0^{*}(100) \dagger$ & $113 \cdot 8 \pm 27 \cdot 5(108)$ & 84 & $\mathrm{p}<0.001$ \\
\hline $\begin{array}{l}\text { SPEP } \\
N \frac{13}{13}\end{array}$ & $13 \cdot 4 \pm 1 \cdot 2$ & $13 \cdot 3 \pm 1 \cdot 4$ & 49 & NS \\
\hline$\frac{C E P}{N \overline{20}}$ & $20 \cdot 6 \pm 1 \cdot 2 \quad(76)$ & $23 \cdot 3 \pm 3 \cdot 0$ & 52 & $\mathrm{p}<0.001$ \\
\hline$P \overline{30}$ & $29.2 \pm 2.5 \quad(76)$ & $35.5 \pm 7.6$ & 50 & $\mathrm{p}<0.001$ \\
\hline
\end{tabular}

*Standard deviation.

†Number of values in each group.

Table 2 Changes in latency of major components of the evoked potentials obtained from a group of 56 patients with clinically definite multiple sclerosis over a two year follow-up period

\begin{tabular}{|c|c|c|c|c|c|c|}
\hline Components & $\begin{array}{l}\text { Patients } \\
\text { First Study }\end{array}$ & $\begin{array}{l}\text { \% patients } \\
\text { abnormal }\end{array}$ & $\begin{array}{l}\text { Time interval } \\
+S D(\text { mth })\end{array}$ & $\begin{array}{l}\text { Patients } \\
\text { Final Study }\end{array}$ & $\begin{array}{l}\text { \% patients } \\
\text { abnormal }\end{array}$ & $P_{2}$ \\
\hline $\begin{array}{l}\text { VEP } \\
100\end{array}$ & $113 \cdot 8 \pm 27 \cdot 5(108)$ & 84 & $31 \cdot 6 \pm 9 \cdot 8$ & $138 \pm 24 \cdot 8(77)$ & 91 & $\mathrm{p}<0.001$ \\
\hline $\begin{array}{l}\text { SPEP } \\
\mathrm{N}\end{array}$ & $13 \cdot 3 \pm 1 \cdot 4$ & 49 & $26 \cdot 3 \pm 7 \cdot 3$ & $13 \cdot 7 \pm 1 \cdot 3(44)$ & 75 & NS \\
\hline $\begin{array}{l}\text { CEP } \\
N \overline{20}\end{array}$ & $23 \cdot 3 \pm 3 \cdot 0$ & 52 & $25 \cdot 8 \pm 7 \cdot 1$ & $24.4 \pm 3.7$ & 76 & $\mathrm{p}<0.05$ \\
\hline$P \overline{30}$ & $35.5 \pm 7.6$ & 50 & $25 \cdot 8 \pm 7 \cdot 1$ & $39.0 \pm 10.6(89)$ & 73 & $\mathrm{p}<0.005$ \\
\hline
\end{tabular}

Table 3 Changes in latency of individual evoked potentials obtained from 56 patients over a two-year follow-up period

\begin{tabular}{lllll}
\hline & $V E P$ & $S P E P$ & & \multicolumn{1}{c}{$C E P$} \\
& $P \overline{100}$ & $N \overline{13}$ & $N \overline{30}$ & \multicolumn{1}{c}{} \\
\hline No change & & & $58 / 100(58 \%)$ & $47 / 104(45 \%)$ \\
Increase & $38 / 112(74 \%)$ & $55 / 94(59 \%)$ & $30 / 100(30 \%)$ & $47 / 104$ \\
Decrease & $65 / 112(58 \%)$ & $39 / 94(42 \%)$ & $12 / 100(12 \%)$ & $10 / 104(10 \%)$ \\
\hline
\end{tabular}

patients without clinical evidence of sensory pathway involvement had at least one abnormal component at the first examination. One or more spinal or cortical response was abnormal in 37 patients $(70 \%)$ and 34 patients $(65 \%)$ had abnormalities of the cortical response alone at the first examination. Fourteen of the patients with normal responses had clinical evidence of sensory disturbance.

\section{Spinal evoked potential}

The mean latency for the spinal evoked potentials in 38 control subjects obtained from stimulating both median neryes was $13.4 \mathrm{~ms}(\mathrm{SD}, 1.2 \mathrm{~ms})$. No correction was made for arm length. The responses from patients were considered abnormal if the latency was greater than $15.8 \mathrm{~ms}$ (mean $+2 \mathrm{SD}$ ) or if the latency difference between the two arms exceeded $1 \mathrm{~ms}$. There were 47 patients with clinically definite multiple sclerosis from whom satisfactory records were made at the first examination. There were 23 patients who had abnormal responses (49\%). Of these there were two patients with one response delayed; one patient with both responses delayed; six patients with one response absent; 10 patients with both responses absent; and in four patients the latency difference between the two sides was greater than $1 \mathrm{~ms}$ but each response was itself within the control range. The mean value for the recorded responses was $13.3 \mathrm{~ms}(\mathrm{SD}, 1.4 \mathrm{~ms})$.

The studies were repeated after a mean interval of 


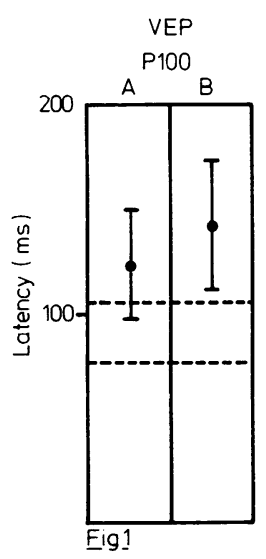

Fig 1 The mean latency and two standard deviations for the P $\overline{100}$ component of the VEP at the beginning $(A)$ and end $(B)$ of the follow-up period. The control range is indicated by dotted lines.

26.3 months (table 2 , fig 2 ), and the mean value for the measurable responses was $13.7 \mathrm{~ms}(\mathrm{SD}, 1.3 \mathrm{~ms})$ which was not increased $(p>0 \cdot 1)$. Thirty-five patients had abnormalities $(75 \%)$, and there were 12 patients in whom the spinal evoked potentials remained within normal limits. At the final examination there were 55 responses which were unchanged, 39 in which the latency had increased and none in which the latency had decreased. There were 23 responses that were obtainable at the first examination but had become unrecordable by the time of the final examination.

\section{Cortical evoked responses}

$N \overline{20}$ component The mean latency for the control group was $20.6 \mathrm{~ms}$ (SD, $1.2 \mathrm{~ms}$ ). The response was considered to be abnormal if the latency was greater than 24 ms (mean +2 SD), or the latency on the two sides differed by $3 \mathrm{~ms}$ or more. There were 50 patients who had responses recorded at the onset of the study, and of these, 26 patients $(52 \%)$ were abnormal; 11 had responses that were prolonged or absent on one side only and 15 were bilaterally abnormal. The mean for the group was $23.3 \mathrm{~ms}$ (SD, $3.0 \mathrm{~ms}$ ). The studies were repeated after a mean interval of 25.8 months and the individual responses were compared (table 2, fig 3 ). Thirty-eight patients had abnormal responses (76\%). Fifty-eight potentials were not significantly altered, 30 had increased latency and 12 had decreased latency (table 3 ). Fifteen responses that had been recorded at the onset of the study became unrecordable by the time of the final examination.
$P 30$ component The mean latency for the control group was $29.2 \mathrm{~ms}$ (SD, $2.5 \mathrm{~ms}$ ). A response was considered to be abnormal if the latency was $36 \mathrm{~ms}$ or greater, or if the difference in the latency of the two sides was $5 \mathrm{~ms}$ or more. There were 52 patients who had satisfactory responses recorded at the onset of the study and of these, 26 were abnormal $(50 \%)$; 15 were abnormal on one side only $(29 \%)$, and 11 were abnormal $(21 \%)$ on both sides. The mean latency for the group was $35.5 \mathrm{~ms}$ (SD, $7.6 \mathrm{~ms}$ ). There were two patients in whom there was no initial negative $(N \overline{20})$ response but in whom the $P \overline{30}$ response was delayed. Follow-up studies were performed after a mean interval of 25.8 months (table 2 , fig 3), when 38 patients had abnormal responses (73\%); 47 responses did not change significantly and the latencies of 10 responses decreased.

\section{Clinical assessment of sensory function}

There were 20 patients who had clinical evidence of an increase in sensory disability at the final assessment, and one or more response had increased in latency or become unrecordable in 17 of these. A further 30 patients were clinically unchanged, but one or more response had increased in latency or disappeared in 25 of these. There were three patients who had clinical evidence of improvement; the cortical responses had reduced latencies in two of these but the spinal responses had become unrecordable in both patients. The responses remained unaltered in the third patient of this group.

BRAIN STEM AUDITORY EVOKED POTENTIALS The technique for recording satisfactory BSAEP was not established until after the onset of the study; measurements were available for only 34 patients. In control subjects the mean latency of wave $V$ was $5.8 \mathrm{~ms}$ ( $\mathrm{SD}, 0.2 \mathrm{~ms}$ ). A response was considered abnormal if it exceeded the upper limit of the control range of $6.2 \mathrm{~ms}$. The inter-ear latency difference for component $\mathrm{V}$ was considered abnormal if it exceeded $0.5 \mathrm{~ms}$. Of the 34 patients studied, 15 had abnormal BSAEP (44\%). There was clinical evidence of brain stem involvement in 22 of the patients studied, 11 of whom had abnormal responses $(50 \%)$. Abnormal responses were obtained from four of the 12 patients who had no clinical evidence of brain stem involvement (33\%).

COMBINED RESULTS OF ALL EVOKED POTENTIAL STUDIES

At the initial examination both visual evoked potentials were normal in nine patients; however, four of these patients had abnormalities of the spinal or cortical evoked potentials. That is, one or more abnormal results were obtained in $91 \%$ of the patients. At 


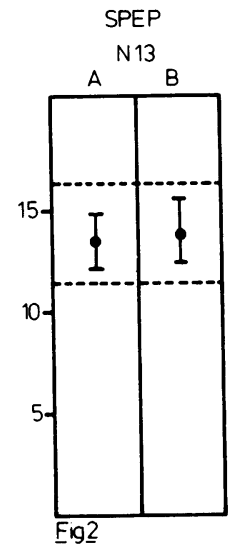

Fig 2 The mean latency and two standard deviations for the $N \overline{13}$ component of the SPEP at the beginning $(A)$ and end $(B)$ of a 2-year follow-up period. The control range is indicated by dotted lines.

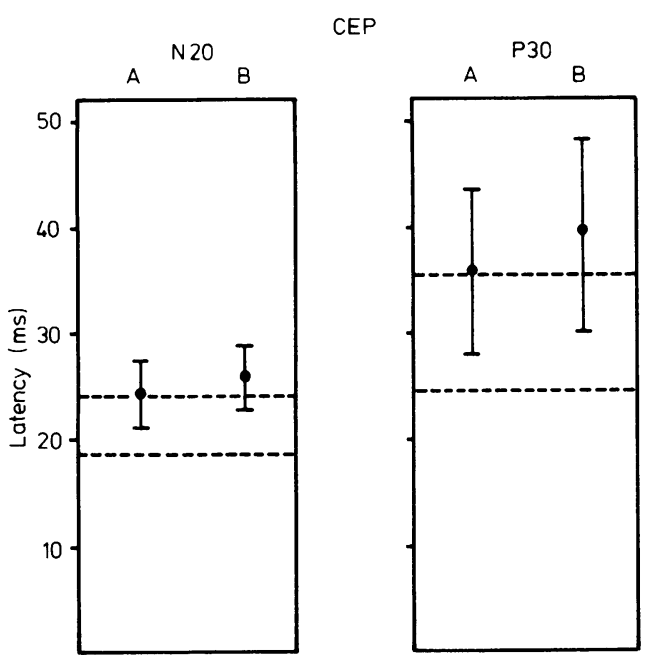

Fig 3 The mean latency and two standard deviations for the $N \overline{20}$ and $P \overline{30}$ components of the CEP at the beginning $(A)$ and end $(B)$ of a 2-year follow-up period. The control ranges are indicated by dotted lines.

the final examination the visual evoked potentials had become abnormal in five of these nine patients; of the four patients with normal evoked potentials there were abnormalities of spinal or somatosensory evoked potentials in three. The BSAEP were normal in this group of four subjects. One or more abnormal results were therefore obtained from $98 \%$ of patients at the final examination.

\section{Discussion}

In the present study of patients with clinically definite multiple sclerosis, the measurement of the latency of the major positive component of the visual evoked response provided the highest yield of abnormalities. However, normal potentials were obtained in $16 \%$ of patients, in three of whom there were objective abnormalities of vision on clinical assessment. The incidence of abnormalities in $84 \%$ of the patients is very similar to that in most of the reports reviewed by Halliday; ${ }^{21}$ some authors have reported a higher incidence of abnormalities but these studies have been performed on smaller groups of patients. ${ }^{1022} \mathrm{We}$ have confined our examination to the absolute latency of the first major positive component and to the inter-ocular latency difference. Although it may be possible to increase the yield of abnormal results by attention to other parameters of the responses, ${ }^{23}{ }^{24}$ it appears that the latency of the $\mathrm{P} \overline{100}$ component is the single most sensitive measure of abnormality, ${ }^{23}$ and is the most easily measured in most laboratories. In addition, it has been clearly demonstrated in the present study that decrease in latency of the VEP is uncommon $(8 \%)$ over a $2 \frac{1 / 2}{2}$ year period, and that examination of the VEP is the most useful single investigation of this type in patients suspected of having multiple sclerosis.

Both spinal and cortical somatosensory evoked responses have been studied in multiple sclerosis, and the results compared with the VEP by several authors, ${ }^{1101221}$ although the degree of diagnostic certainty in patients in some studies is unclear. Abnormalities in the SPEP appear to be common. ranging from $60 \%$ to $94 \%$ in some studies, ${ }^{6-821}$ and Small et $a^{6}$ suggest that this sub-cortical response is more often abnormal than the cortical response. In our study, $49 \%$ of patients had one or more abnormal SPEP at the first examination. Over a two-year period, 24 of the 68 originally recordable responses became unrecordable and no response had a shortened latency.

The Rolandic CEP examination was confined to the $\mathrm{N} \overline{20}$ and $\mathrm{P} \overline{30}$ component because of their reproducibility in the one individual from occasion to occasion. At the first examination abnormalities of one or more components of the CEP were found in $65 \%$ of patients, and these findings may be compared with the range of $50 \%$ to $85 \%$ in other reports, summarised by Halliday. ${ }^{1}$ It should be emphasised however that at the end of the follow up period 30 of $98 \mathrm{~N} \overline{20}$ responses, and 47 of $104 \mathrm{P} \overline{30}$ responses had latencies that had increased significantly since the first examination; many of these patients had no change clinically in sensory 
function, suggesting that the use of repeated studies of sensory evoked responses in patients with a suspected diagnosis of multiple sclerosis may provide useful information if the initial studies are normal. Trojaborg and Petersen ${ }^{10}$ reported a higher yield of abnormalities with peroneal nerve stimulation.

Some apparent improvement in the cortical evoked potential was noted occasionally, but this did not correlate well with a change in clinical status. However, in most cases the decrease in latency was small; in other cases the appearance of a peak at a shorter latency was often associated with a response of lower amplitude and less complicated wave form. Matthews and Small ${ }^{15}$ reported in a study that combined both definite and probable categories of multiple sclerosis that both visual and spinal evoked potentials may return to normal. The BSAEP is also known to have a high incidence of abnormalities in multiple sclerosis. 1122125 The BSAEP recordings were limited in the present study as the investigation was introduced in the laboratory toward the end of the trial period. However, $44 \%$ of patients were found at the final examination to have one or both responses abnormal when considering the latency of wave $\mathrm{V}$ alone, and this is similar to the findings of other workers. ${ }^{1226}$

In general, the incidence of abnormalities in the different types of evoked responses in our study is similar to that reported by other workers, and the highest yield of abnormal responses is obtained from the visual system. It is important to note however, that combined evoked response studies increased the yield of abnormal responses, so that at the first assessment $91 \%$ of patients had abnormalities of one or more evoked responses. All responses tended to increase in latency with time, including responses obtained from the three patients who had clinically improved. At the final examination $98 \%$ of patients had one or more abnormal response. The single patient with all normal responses had been clinically normal throughout the period of observation in spite of a clearly documented history of definite multiple sclerosis prior to the trial period. It is concluded therefore that combined evoked potential measurements have an important place in the investigation of suspected multiple sclerosis, and that repeat studies will be worthwhile if clinical doubt persists. The progression of electrophysiological abnormalities correlated with the clinical progression of the disease, since in this group of patients, the mean increase in clinical disability was $1.3(\mathrm{SD}, 1.5)$ on the Kurtzke Disability Scale over a two-year period. ${ }^{20}$

We gratefully acknowledge the financial support of the National Health and Medical Rasearch Council and Steven Burrows for expert technical assistance.

\section{References}

' Halliday AM. Clinical application of evoked potentials. In: Matthews WB, Glaser GH, eds. Recent Advances in Clinical Neurology. Edinburgh: Churchill Livingstone, 1978:47-73.

${ }^{2}$ Starr A. Sensory evoked potentials in clinical disorders of the nervous system. Ann Rev Neurosci 1978;1:103-27.

${ }^{3}$ Halliday AM, McDonald WI, Mushin J. Visual evoked response in diagnosis of multiple sclerosis. $\mathrm{Br}$ Med J 1973;4:661-4.

4 Asselman P, Chadwick DW, Marsden CD. Visual evoked responses in the diagnosis and management of patients suspected of multiple sclerosis. Brain 1975;98:261-82.

${ }^{5}$ Matthews WB, Small DG, Small M, Pountney E. The pattern-reversal evoked visual potential in the diagnosis of multiple sclerosis. J Neurol Neurosurg Psychiatry 1977;40:1009-14.

- Small DG, Matthews WB, Small M. The cervical somatosensory evoked potential (SEP) in the diagnosis of multiple sclerosis. J Neurol Sci 1978;35:211-24.

' Mastaglia FL, Black JL, Collins DWK. Visual and spinal evoked potentials in diagnosis of multiple sclerosis. $\mathrm{Br}$ Med J 1976;3:732.

8 Namerow NW. Somatosensory evoked responses in multiple sclerosis patients with varying sensory loss. Neurology (Minneap) 1968;18:1197-204.

' Eisen A, Stewart J, Nudelman K, Cosgrove JBR. Short latency somatosensory responses in multiple sclerosis. Neurology (NY) 1979;29:827-34.

${ }^{10}$ Trojaborg W, Petersen E. Visual and somatosensory evoked cortical potentials in multiple sclerosis. $J$ Neurol Neurosurg Psychiatry 1979;42:323-30.

"Robinson K, Rudge P. Abnormalities of auditory evoked potentials in patients with multiple sclerosis. Brain 1977;100:19-40.

${ }^{12}$ Chiappa KH. Pattern shift visual, brainstem auditory, and short-latency somatosensory evoked potentials in multiple sclerosis. Neurology (NY) 1980;30:110-23.

${ }^{13}$ Khoshbin S, Hallett M. Multimodality evoked potentials and blink reflex in multiple sclerosis. Neurology (NY) 1981;31:138-44.

${ }_{14}$ Purves SJ, Low MD, Galloway J, Reeves B. A comparison of visual, brain-stem auditory, and somatosensory evoked potentials in multiple sclerosis. Can J Neurol Sci 1981;8:15-19.

is Matthews WB, Small DG. Serial recordings of visual and somatosensory evoked potentials in multiple sclerosis. J Neurol Sci 1979;40:11-21.

${ }^{16}$ Robinson K, Rudge P. The stability of the auditory evoked potentials in normal man and patients with multiple sclerosis. J Neurol Sci 1978;36:147-56.

${ }^{17}$ Kjaer M. Variations of brain stem auditory evoked potentials correlated to duration and severity of multiple sclerosis. Acta Neurol Scand 1980;61:157-66.

${ }^{18}$ Confavreux Ch, Mauguiere F, Courjon J, Aimard G, 
Devic M. Evolutions des potentiels évoqués visuels dans la sclérose en plaques. Rev Neurol (Paris) 1981;137:121-32.

${ }^{19}$ McDonald WI, Halliday AM. Diagnosis and classification of multiple sclerosis. $\mathrm{Br}$ Med Bull 1977;33:4-8.

${ }^{20}$ Basten A, McLeod JG, Pollard JD, et al. Transfer factor in the treatment of multiple sclerosis. Lancet 1980;2:931-4.

${ }^{21}$ Halliday AM. New developments in the clinical application of evoked potentials, In: Cobb WA, Van Duijn $\mathrm{H}$, eds. Contemporary Clinical Neurophysiology. Amsterdam: Elsevier, 1978:105-21.

${ }^{22}$ Chain F, Mallecourt J, Leblanc N, Lhermitte F. Apport de l'enregistrement des potentiels évoqués visuels au diagnostic de la sclérose en plaques. Rev Neurol (Paris) 1977;133:81-8.

${ }^{23}$ Collins DWK, Black JL, Mastaglia FL. Pattern reversal visual evoked potential. Method of analysis and results in multiple sclerosis. $J$ Neurol Sci 1978;36:83-95.

${ }^{24}$ Tackmann W, Strenge H, Barth R, Sojka-Raytscheff A. Diagnostic validity for different components of pattern shift visual evoked potentials in multiple sclerosis. Eur Neurol 1979;18:243-8.

${ }^{25}$ Starr A, Achor J. Auditory brainstem responses in neurological disease. Arch Neurol 1975;32:761-8.

${ }^{26}$ Chiappa KH, Harrison JL, Brooks EB, Young RR. Brainstem auditory evoked responses in 200 patients with multiple sclerosis. Ann Neurol 1980;7:135-43. 